\title{
DESARROLLO DE LAS COMPETENCIAS COMUNICATIVAS EN ESTUDIANTES DE ZOOTECNIA DE LA UFPSO
}

\section{COMMUNICATION SKILLS DEVELOPMENT IN STUDENTS OF ZOOTECNIA UFPSO}

\author{
MSc. (C) Cesar Augusto Urón Castro ${ }^{\text {a }}$, Maira Alejandra Urón \\ ${ }^{a}$ Universidad Francisco de Paula Santander Ocaña, Grupo de Investigación GI@DS \\ Vía Acolsure, Sede el Algodonal, Ocaña, Colombia, cauronc@ufpso.edu.co
}

Fecha de recepción: 05-02-2016

Fecha de aprobación: 17-05-2016

\begin{abstract}
Resumen: Las competencias comunicativas constituyen una herramienta fundamental en la formación del profesional de la Zootecnia, desde el plano de su integralidad y desarrollo del campo ocupacional. Desde esta posición, se realizó un acercamiento conceptual tomando como base los postulados de diversos autores, especialmente el enfoque de Paul Ricoeur, que muestra la importancia del conocerse a sí mismo y cómo se constituye el hombre capaz.
\end{abstract}

Para tener un panorama más exacto, se aplicó a todos los estudiantes del programa de zootecnia un cuestionario formulado sobre las bases de la expresión oral y escrita extraído de la operatividad de la investigación, se utilizó el método cuantitativo, la información obtenida fue tabulada y analizada con el software SPSS versión 15. Los resultados arrojaron gran dificultad en la utilización de las competencias comunicativas para favorecer la integralidad del perfil profesional, permitiéndonos por medio de otras investigaciones crear un plan de mejora desde el pensum.

Palabras clave: formación, integralidad, pedagogía, percepción, subjetividad

Abstract: from the plane of its integrity and development of the occupational field. From this position, a conceptual approach based on the principles of various authors, especially the approach of Paul Ricoeur, which shows the importance of knowing yourself and how man is capable is performed.

To get a more accurate picture, all program students zootecnia a formulated on the basis of oral and written expression extracted from the operation of the research questionnaire quantitative method was used was applied, the information obtained was tabulated and analyzed with SPSS software version 15. Results showed great difficulty in using communication skills to promote the integrity of the professional profile, allowing other research by creating an improvement plan from the curriculum. 
Keywords: comprehensiveness,, perception, subjectivity, teaching, training,

\section{INTRODUCCIÓN}

Todos los grupos humanos, incluso los de animales, se organizan entre sí mediante la comunicación o conjunto de actuaciones con las que entablan contacto para transmitirse información. Existe una enorme variedad de actos de comunicación: la sonrisa de un niño, el abrazo de un amigo, el ladrido de un perro, las danzas de las abejas, los cantos de las ballenas, etc., hasta los nuevos robots entienden y responden con mensajes o con la ejecución de las acciones solicitadas, como parece que también hacen los genes. Es decir, que en diferentes y múltiples planos, situaciones o necesidades existe algo o alguien que asume el papel de emisor, quien mediante un código compartido, emite un mensaje a cierto receptor o receptores a través de distintos canales. Obviamente, cuantos más lenguajes compartan emisor y receptor, mayores y más ricas posibilidades tendrán de una comunicación satisfactoria, de comprender y expresar la realidad y la fantasía de forma multifacética, tal como ocurre con un cuento ilustrado, un poema cantado, una película, una información científica presentada con power point o el documental de un suceso histórico.

La posibilidad de desplegar diversos lenguajes además del verbal, aun en el caso de que resulten redundantes en parte, suele ayudar al receptor en su descodificación, ya que compensa los efectos del ruido en cuanto a perturbación de la comprensión.
Esto además resulta una prueba de humildad que parte de reconocer lo finito o parcial del saber ante lo infinito o complejo de la realidad y las limitaciones que podamos tener como emisores y receptores. Al fin, la cultura (y el desenvolvimiento del día a día) es un gran texto multicodificado, que las sucesivas generaciones vamos reinterpretando $\mathrm{y}$ enriqueciendo. Anulada la comunicación, el ser humano se desestructuraría mentalmente. Por todo esto, los métodos educativos no deben reducirse a proponer imitaciones, reiteraciones, respuestas automáticas que nunca conducen a expandir el pensamiento divergente ni la capacidad crítica y creativa.

La competencia comunicativa así concebida debe servir para recoger información del entorno con el fin de aportar una respuesta activa y personal, única. Convertirla en algo pasivo o trivial es un error, un derroche y un aburrimiento. La competencia comunicativa implica el uso eficaz de un sistema complejo de lenguajes y códigos interdependientes, el cual permite a un sujeto estar en contacto más o menos constante a través de múltiples signos y señales, sin descartar el principal que es el lenguaje verbal (oral y escrito).

Se debe ser competentes para leer el mundo, el cosmos, que en la actualidad se representa también como un gran ser vivo, expresivo, o como un enorme panel informático; esta comunicación puede 
aportarnos rasgos de lo inaccesible o inimaginable, de manera que todo lo existente quepa en nosotros y que cada ser humano pueda trasladar sus pensamientos, emociones, ruegos, fantasías o sugerencias a los demás. Ya se ha sostenido que la comunicación se apoya en todos los lenguajes, entendiendo por tales aquellos que manifiestan algo mediante cierto código (tal como la música, las señales de tráfico, las matemáticas, la arquitectura, la moda), si bien la lengua, en cuanto lenguaje natural, es en la que según Reyzábal (2012) “(...)todas las otras se dejan traducir". Por eso se habla de dos clases de elementos de mediación con la realidad: la lengua y las herramientas; estas modifican el entorno y aquella a las personas.

\section{METODOLOGÍA}

Para la realización de esta investigación se acudió al tipo de investigación descriptiva, con el propósito de identificar las variables que inciden en la capacidad oral y escrita de los estudiantes del programa de Zootecnia, en todos sus semestres, de la Facultad de Ciencias Agrarias y del Ambiente.

La investigación se encuentra inmersa en el área de las ciencias sociales o del comportamiento humano toda vez toda vez que describe una situación o evento real, con el objetivo principal de comprenderlo mejor.

La investigación es social analizada dentro del modelo cuantitativo está directamente basada en el paradigma explicativo. Éste utiliza preferentemente información cuantitativa o cuantificable para describir o tratar de explicar los fenómenos que estudia, en las formas que es posible hacerlo en el nivel de estructuración lógica en el cual se encuentran las ciencias sociales actuales.

El proceso de toma de medidas es básico en la investigación cuantitativa ya que aporta la conexión fundamental entre la observación empírica, y la expresión matemática, es decir, mostrar en números y gráficos lo que se ha observado.

Todos los experimentos cuantitativos utilizan un formato estándar, con algunas pequeñas diferencias inter-disciplinarias para generar una hipótesis que será probada o desmentida. Esta hipótesis debe ser demostrable por medios matemáticos y estadísticos y constituye la base alrededor de la cual se diseña todo el experimento.

La asignación al azar de un grupo de estudio es esencial y se debe incluir un grupo de control, siempre que sea posible. La investigación cuantitativa realiza preguntas específicas y de las respuestas de los participantes, obtiene muestras numéricas.

La información obtenida es analizada con la ayuda de la estadística, de la informática y de la matemática, buscando obtener un resultado que luego pueda generalizarse a una población mayor que a la muestra acotada que ha utilizado en sus observaciones.

La población de esta investigación estuvo conformada por los doscientos cincuenta y un (251) estudiantes pertenecientes a todos 
los semestres del programa de Zootecnia de la Facultad de Ciencias Agrarias y del Ambiente de la UFPS Ocaña, según datos extraidos del Sistema de Información Académica SIA. Por tratarse de una población pequeña, la muestra equivalió a la totalidad de los estudiantes.

El instrumento utilizado para recopilar la información fue la encuesta, la cual se les aplicó a todos los estudiantes de Zootecnia de todos los semestres, géneros y edades a los cuales se les preguntó sobre la utilización y aplicación de las competencias comunicativas desde la expresión oral y escrita en su formación como zootecnistas.

\section{RESULTADOS}

La encuesta se realizó a la totalidad de estudiantes del programa, para un total de 251, discriminados así:

Tabla 1. Encuestas realizadas

\begin{tabular}{ccc}
\hline GENERO & Femenino & $\mathbf{9 2}$ \\
\hline & Masculino & 159 \\
\hline \multirow{2}{*}{ EDAD } & 17 a 20 & 203 \\
\cline { 2 - 3 } & 21 a 22 & 42 \\
\cline { 2 - 3 } SEMESTRE & 23 a 25 & 6 \\
\cline { 2 - 3 } & 1 & 81 \\
\cline { 2 - 3 } & 2 & 39 \\
\hline & 3 & 23 \\
\hline & 4 & 25 \\
\hline & 5 & 15 \\
\hline & 6 & 19 \\
\cline { 2 - 3 } & 7 & 6 \\
\hline & 8 & 17 \\
\hline
\end{tabular}

Fuente: autor

Los resultados obtenidos desde el instrumento fueron analizados en el software SPSS versión quince, los cuales para facilidad del mismo se codificaron desde los diferentes factores que se van a evaluar con el fin de hacer más fácil el análisis de la información.

Tabla 2. Frecuencia total de calificación de encuestas aplicadas

\begin{tabular}{clrrrr}
\hline & Frecuencia & Porcentaje & $\begin{array}{c}\text { Porcentaje } \\
\text { válido }\end{array}$ & $\begin{array}{c}\text { Porcentaje } \\
\text { acumulado }\end{array}$ \\
\hline Válidos & nunca & 1240 & 14.5 & 14.5 & 14.5 \\
\cline { 2 - 6 } & rara vez & 1359 & 15.9 & 15.9 & 30.5 \\
\cline { 2 - 6 } & a veces & 2016 & 23.6 & 23.6 & 54.1 \\
\cline { 2 - 6 } a menudo & 1984 & 23.2 & 23.2 & 77.3 \\
\cline { 2 - 6 } & siempre & 1935 & 22.7 & 22.7 & 100.0 \\
\cline { 2 - 6 } & Total & 8534 & 100.0 & 100.0 & \\
\hline
\end{tabular}

Fuente: autor

Tabla 3. Frecuencia por género

\begin{tabular}{llrrrr}
\hline & Frecuencia & Porcentaje & $\begin{array}{c}\text { Porcentaj } \\
\text { e válido }\end{array}$ & \multicolumn{2}{c}{$\begin{array}{c}\text { Porcentaje } \\
\text { acumulado }\end{array}$} \\
\hline Válidos & masculino & 5406 & 63.3 & 63.3 & 63.3 \\
\cline { 2 - 6 } & femenino & 3128 & 36.7 & 36.7 & 100.0 \\
\cline { 2 - 6 } & Total & 8534 & 100.0 & 100.0 & \\
\hline
\end{tabular}

Fuente: autor

Tabla 4. Frecuencia por edad

\begin{tabular}{llrrrr}
\hline & Frecuencia & Porcentaje & $\begin{array}{c}\text { Porcentaje } \\
\text { válido }\end{array}$ & $\begin{array}{r}\text { Porcentaje } \\
\text { acumulado }\end{array}$ \\
\hline Válidos & $\begin{array}{l}17 \text { a 20 } \\
\text { años }\end{array}$ & 6902 & 80.9 & 80.9 & 80.9 \\
\cline { 2 - 6 } $\begin{array}{l}21 \text { a } 22 \\
\text { años }\end{array}$ & 1417 & 16.6 & 16.6 & 97.5 \\
$\begin{array}{l}\text { 23 a 25 } \\
\text { años }\end{array}$ & 215 & 2.5 & 2.5 & 100.0 \\
\hline Total & 8534 & 100.0 & 100.0 & \\
\hline
\end{tabular}

Fuente: autor

Tabla 5. Frecuencia por semestre

\begin{tabular}{|c|c|c|c|c|c|}
\hline & & $\begin{array}{c}\text { Frecuenci } \\
\mathrm{a}\end{array}$ & Porcentaje & $\begin{array}{l}\text { Porcentaje } \\
\text { válido }\end{array}$ & $\begin{array}{l}\text { Porcentaje } \\
\text { acumulado }\end{array}$ \\
\hline \multirow[t]{11}{*}{ Válidos } & Sem 1 & 2754 & 32.3 & 32.3 & 32.3 \\
\hline & Sem 2 & 1326 & 15.5 & 15.5 & 47.8 \\
\hline & Sem 3 & 782 & 9.2 & 9.2 & 57.0 \\
\hline & Sem 4 & 850 & 10.0 & 10.0 & 66.9 \\
\hline & Sem 5 & 510 & 6.0 & 6.0 & 72.9 \\
\hline & Sem 6 & 646 & 7.6 & 7.6 & 80.5 \\
\hline & Sem 7 & 204 & 2.4 & 2.4 & 82.9 \\
\hline & Sem 8 & 578 & 6.8 & 6.8 & 89.6 \\
\hline & Sem 9 & 578 & 6.8 & 6.8 & 96.4 \\
\hline & Sem 10 & 306 & 3.6 & 3.6 & 100.0 \\
\hline & Total & 8534 & 100.0 & 100.0 & \\
\hline
\end{tabular}


Fuente: autor

Tabla 6. Pruebas de chi-cuadrado por género

\begin{tabular}{|c|c|c|c|c|}
\hline Genero & & Valor & gl & $\begin{array}{c}\text { Sig. } \\
\text { asintótica } \\
\text { (bilateral) }\end{array}$ \\
\hline \multirow[t]{4}{*}{ Masculino } & $\begin{array}{l}\text { Chi-cuadrado de } \\
\text { Pearson }\end{array}$ & $50.233^{\mathrm{a}}$ & 4 & .000 \\
\hline & $\begin{array}{l}\text { Razón de } \\
\text { verosimilitudes }\end{array}$ & 54.055 & 4 & .000 \\
\hline & $\begin{array}{l}\text { Asociación lineal } \\
\text { por lineal }\end{array}$ & 47.892 & 1 & .000 \\
\hline & $\mathrm{N}$ de casos válidos & 318 & & \\
\hline \multirow[t]{4}{*}{ Femenino } & $\begin{array}{l}\text { Chi-cuadrado de } \\
\text { Pearson }\end{array}$ & $23.727^{\mathrm{b}}$ & 4 & .000 \\
\hline & $\begin{array}{l}\text { Razón de } \\
\text { verosimilitudes }\end{array}$ & 28.469 & 4 & .000 \\
\hline & $\begin{array}{l}\text { Asociación lineal } \\
\text { por lineal }\end{array}$ & 21.629 & 1 & .000 \\
\hline & N de casos válidos & 184 & & \\
\hline
\end{tabular}

a 5 .

a. 0 casillas $(0 \%)$ tienen una frecuencia esperada inferior

La frecuencia mínima esperada es 8,00 .

b. 2 casillas $(20,0 \%)$ tienen una frecuencia esperada

inferior a 5 .

La frecuencia mínima esperada es 3,50.

Fuente: autor

El test de $\mathrm{X}^{2}$ chi-cuadrado efectúa un contraste de hipótesis para determinar si se rechaza o acepta la idea de que la fila (preguntas) y la columna (Calificación escala) de la referencia pruebas de chí cuadrado son independientes. Se ve que el valor de p-value (significación asintótica) bilateral es inferior al 0,05 se puede rechazar la hipótesis de que las filas y columnas son independientes con un nivel de confianza del 95\%, por tanto las filas estudiadas tienen relación con la calificación (columna).

Tabla 7. Prueba de chí-cuadrado por edad

\begin{tabular}{|c|c|c|c|c|c|c|}
\hline Edad & & Valor & gl & $\begin{array}{l}\text { Sig. } \\
\text { asintótica } \\
\text { (bilateral) }\end{array}$ & $\begin{array}{l}\text { Sig. exacta } \\
\text { (bilateral) }\end{array}$ & $\begin{array}{l}\text { Sig. exacta } \\
\text { (unilateral) }\end{array}$ \\
\hline \multirow[t]{3}{*}{$\begin{array}{l}17 \text { a } 20 \\
\text { ã̃os }\end{array}$} & $\begin{array}{l}\text { Chi-cuadrado de } \\
\text { Pearson }\end{array}$ & $58.613^{\mathrm{a}}$ & 4 & .000 & & \\
\hline & $\begin{array}{l}\text { Razón de } \\
\text { verosimilitudes }\end{array}$ & 65.507 & 4 & .000 & & \\
\hline & $\begin{array}{l}\text { Asociación } \\
\text { lineal por lineal }\end{array}$ & 54.829 & 1 & .000 & & \\
\hline
\end{tabular}

\begin{tabular}{|c|c|c|c|c|}
\hline & $\begin{array}{l}\mathrm{N} \text { de casos } \\
\text { válidos }\end{array}$ & 406 & & \\
\hline \multirow[t]{4}{*}{$\begin{array}{l}21 \text { a } 22 \\
\text { años }\end{array}$} & $\begin{array}{l}\text { Chi-cuadrado de } \\
\text { Pearson }\end{array}$ & $16.387^{b}$ & 4 & .003 \\
\hline & $\begin{array}{l}\text { Razón de } \\
\text { verosimilitudes }\end{array}$ & 18.736 & 4 & .001 \\
\hline & $\begin{array}{l}\text { Asociación } \\
\text { lineal por lineal }\end{array}$ & 15.030 & 1 & .000 \\
\hline & $\begin{array}{l}\mathrm{N} \text { de casos } \\
\text { válidos }\end{array}$ & 84 & & \\
\hline \multirow[t]{10}{*}{$\begin{array}{l}23 \text { a } 25 \\
\text { años }\end{array}$} & $\begin{array}{l}\text { Chi-cuadrado de } \\
\text { Pearson }\end{array}$ & $1.091^{\mathrm{c}}$ & 1 & .296 \\
\hline & $\begin{array}{l}\text { Corrección por } \\
\text { continuidad }\end{array}$ & .000 & 1 & 1.000 \\
\hline & $\begin{array}{l}\text { Razón de } \\
\text { verosimilitudes }\end{array}$ & 1.477 & 1 & .224 \\
\hline & $\begin{array}{l}\text { Estadístico } \\
\text { exacto de Fisher }\end{array}$ & & & 1.000 \\
\hline & $\begin{array}{l}\text { Asociación } \\
\text { lineal por lineal }\end{array}$ & 1.000 & 1 & .317 \\
\hline & $\begin{array}{l}\mathrm{N} \text { de casos } \\
\text { válidos }\end{array}$ & 12 & & \\
\hline & \multicolumn{4}{|c|}{$\begin{array}{l}\text { a. } 0 \text { casillas }(, 0 \%) \text { tienen una frecuencia esperada inferior a } 5 \text {. La } \\
\text { frecuencia mínima esperada es } 9,00 .\end{array}$} \\
\hline & \multicolumn{4}{|c|}{$\begin{array}{l}\text { b. } 6 \text { casillas }(60,0 \%) \text { tienen una frecuencia esperada inferior a } 5 . \mathrm{La} \\
\text { frecuencia mínima esperada es } 2,50 \text {. }\end{array}$} \\
\hline & \multicolumn{4}{|c|}{$\begin{array}{l}\text { c. } 2 \text { casillas }(50,0 \%) \text { tienen una frecuencia esperada inferior a } 5 \text {. La } \\
\text { frecuencia mínima esperada es }, 50 \text {. }\end{array}$} \\
\hline & \multicolumn{4}{|c|}{ d. Calculado sólo para una tabla de $2 \times 2$. } \\
\hline
\end{tabular}

Fuente: autor

Tabla 8. Prueba de chi-cuadrado por semestre

\begin{tabular}{|c|c|c|c|c|}
\hline \multicolumn{2}{|c|}{ Semestre } & \multirow{2}{*}{$\frac{\text { Valor }}{39.528^{\mathrm{a}}}$} & \multirow{2}{*}{$\frac{\mathrm{gl}}{4}$} & Sig. asintótica (bilateral) \\
\hline $\begin{array}{l}\text { Sem } \\
1\end{array}$ & $\begin{array}{l}\text { Chi-cuadrado } \\
\text { de Pearson }\end{array}$ & & & .000 \\
\hline & $\begin{array}{l}\text { Razón de } \\
\text { verosimilitudes }\end{array}$ & 46.104 & 4 & .000 \\
\hline & $\begin{array}{l}\text { Asociación } \\
\text { lineal por lineal }\end{array}$ & 26.264 & 1 & .000 \\
\hline & $\begin{array}{l}\mathrm{N} \text { de casos } \\
\text { válidos }\end{array}$ & 162 & & \\
\hline \multirow[t]{4}{*}{$\begin{array}{l}\text { Sem } \\
2\end{array}$} & $\begin{array}{l}\text { Chi-cuadrado } \\
\text { de Pearson }\end{array}$ & $15.762^{\mathrm{b}}$ & 4 & .003 \\
\hline & $\begin{array}{l}\text { Razón de } \\
\text { verosimilitudes }\end{array}$ & 19.372 & 4 & .001 \\
\hline & $\begin{array}{l}\text { Asociación } \\
\text { lineal por lineal }\end{array}$ & 13.640 & 1 & .000 \\
\hline & $\begin{array}{l}\mathrm{N} \text { de casos } \\
\text { válidos }\end{array}$ & 78 & & \\
\hline \multirow[t]{4}{*}{$\begin{array}{l}\text { Sem } \\
3\end{array}$} & $\begin{array}{l}\text { Chi-cuadrado } \\
\text { de Pearson }\end{array}$ & $9.926^{\mathrm{c}}$ & 4 & .042 \\
\hline & $\begin{array}{l}\text { Razón de } \\
\text { verosimilitudes }\end{array}$ & 13.037 & 4 & .011 \\
\hline & $\begin{array}{l}\text { Asociación } \\
\text { lineal por lineal }\end{array}$ & 6.999 & 1 & .008 \\
\hline & $\begin{array}{l}\mathrm{N} \text { de casos } \\
\text { válidos }\end{array}$ & 46 & & \\
\hline $\begin{array}{l}\text { Sem } \\
4\end{array}$ & $\begin{array}{l}\text { Chi-cuadrado } \\
\text { de Pearson }\end{array}$ & $10.500^{d}$ & 4 & .033 \\
\hline
\end{tabular}




\begin{tabular}{|c|c|c|c|c|}
\hline & $\begin{array}{l}\text { Razón de } \\
\text { verosimilitudes }\end{array}$ & 13.268 & 4 & .010 \\
\hline & $\begin{array}{l}\text { Asociación } \\
\text { lineal por lineal }\end{array}$ & 9.932 & 1 & .002 \\
\hline & $\begin{array}{l}\text { N de casos } \\
\text { válidos }\end{array}$ & 50 & & \\
\hline $\begin{array}{l}\text { Sem } \\
5\end{array}$ & $\begin{array}{l}\text { Chi-cuadrado } \\
\text { de Pearson }\end{array}$ & $3.429^{\mathrm{e}}$ & 4 & .489 \\
\hline & $\begin{array}{l}\text { Razón de } \\
\text { verosimilitudes }\end{array}$ & 4.589 & 4 & .332 \\
\hline & $\begin{array}{l}\text { Asociación } \\
\text { lineal por lineal }\end{array}$ & .546 & 1 & .460 \\
\hline & $\begin{array}{l}\mathrm{N} \text { de casos } \\
\text { válidos }\end{array}$ & 30 & & \\
\hline $\begin{array}{l}\text { Sem } \\
6\end{array}$ & $\begin{array}{l}\text { Chi-cuadrado } \\
\text { de Pearson }\end{array}$ & $5.036^{\mathrm{c}}$ & 4 & .284 \\
\hline & $\begin{array}{l}\text { Razón de } \\
\text { verosimilitudes }\end{array}$ & 5.879 & 4 & .208 \\
\hline & $\begin{array}{l}\text { Asociación } \\
\text { lineal por lineal }\end{array}$ & 4.631 & 1 & .031 \\
\hline & $\begin{array}{l}\mathrm{N} \text { de casos } \\
\text { válidos }\end{array}$ & 38 & & \\
\hline $\begin{array}{l}\text { Sem } \\
7\end{array}$ & $\begin{array}{l}\text { Chi-cuadrado } \\
\text { de Pearson }\end{array}$ & $8.800^{\mathrm{f}}$ & 3 & .032 \\
\hline & $\begin{array}{l}\text { Razón de } \\
\text { verosimilitudes }\end{array}$ & 11.632 & 3 & .009 \\
\hline & $\begin{array}{l}\text { Asociación } \\
\text { lineal por lineal }\end{array}$ & 2.957 & 1 & .086 \\
\hline & $\begin{array}{l}\mathrm{N} \text { de casos } \\
\text { válidos }\end{array}$ & 12 & & \\
\hline $\begin{array}{l}\text { Sem } \\
8\end{array}$ & $\begin{array}{l}\text { Chi-cuadrado } \\
\text { de Pearson }\end{array}$ & $8.909^{\mathrm{g}}$ & 3 & .031 \\
\hline & $\begin{array}{l}\text { Razón de } \\
\text { verosimilitudes }\end{array}$ & 10.387 & 3 & .016 \\
\hline & $\begin{array}{l}\text { Asociación } \\
\text { lineal por lineal }\end{array}$ & 6.818 & 1 & .009 \\
\hline & $\begin{array}{l}\mathrm{N} \text { de casos } \\
\text { válidos }\end{array}$ & 34 & & \\
\hline $\begin{array}{l}\text { Sem } \\
9\end{array}$ & $\begin{array}{l}\text { Chi-cuadrado } \\
\text { de Pearson }\end{array}$ & $7.287^{\mathrm{h}}$ & 2 & .026 \\
\hline & $\begin{array}{l}\text { Razón de } \\
\text { verosimilitudes }\end{array}$ & 9.615 & 2 & .008 \\
\hline & $\begin{array}{l}\text { Asociación } \\
\text { lineal por lineal }\end{array}$ & .841 & 1 & .359 \\
\hline & $\begin{array}{l}\mathrm{N} \text { de casos } \\
\text { válidos }\end{array}$ & 34 & & \\
\hline $\begin{array}{l}\text { Sem } \\
10\end{array}$ & $\begin{array}{l}\text { Chi-cuadrado } \\
\text { de Pearson }\end{array}$ & $1.000^{\mathrm{i}}$ & 2 & .607 \\
\hline & $\begin{array}{l}\text { Razón de } \\
\text { verosimilitudes }\end{array}$ & 1.014 & 2 & .602 \\
\hline & $\begin{array}{l}\text { Asociación } \\
\text { lineal por lineal }\end{array}$ & .810 & 1 & .368 \\
\hline & $\begin{array}{l}\mathrm{N} \text { de casos } \\
\text { válidos }\end{array}$ & 18 & & \\
\hline $\begin{array}{l}\text { a. } 2 \mathrm{c} \\
\mathrm{La} \mathrm{fr}\end{array}$ & $\begin{array}{l}\text { casillas }(20,0 \%) \text { ti } \\
\text { ecuencia mínima }\end{array}$ & $\begin{array}{l}\text { na frecu } \\
\text { da es } 2 \text {, }\end{array}$ & & \\
\hline $\begin{array}{l}\text { b. } 6 \text { c } \\
\text { La fr }\end{array}$ & $\begin{array}{l}\text { casillas }(60,0 \%) \\
\text { ecuencia mínima }\end{array}$ & $\begin{array}{l}\text { na frecu } \\
\text { da es } 2 \text {, }\end{array}$ & & \\
\hline
\end{tabular}

c. 8 casillas $(80,0 \%)$ tienen una frecuencia esperada inferior a 5 . La frecuencia mínima esperada es 1,00 .

d. 8 casillas $(80,0 \%)$ tienen una frecuencia esperada inferior a 5. La frecuencia mínima esperada es 1,50.

e. 8 casillas $(80,0 \%)$ tienen una frecuencia esperada inferior a 5 . La frecuencia mínima esperada es ,50.

f. 8 casillas $(100,0 \%)$ tienen una frecuencia esperada inferior a 5 La frecuencia mínima esperada es 1,00.

g. 6 casillas $(75,0 \%)$ tienen una frecuencia esperada inferior a 5 . La frecuencia mínima esperada es 1,50.

h. 4 casillas $(66,7 \%)$ tienen una frecuencia esperada inferior a 5 . La frecuencia mínima esperada es 2,50.

i. 4 casillas $(66,7 \%)$ tienen una frecuencia esperada inferior a 5 . La frecuencia mínima esperada es 1,50.

Fuente: autor

\section{CONCLUSIONES}

Analizados los resultados obtenidos se puede concluir que es necesario el desarrollo de un estudio que permita validar el uso y desarrollo de las competencias comunicativas en los estudiantes del programa de Zootecnia, ya que como se evidencia existen muchas falencias y puntos por reforzar.

Los estudiantes en todos los semestres muestran una dificultas visible dentro de la utilización de la expresión escrita siendo transversal en la diferencia de genero por edades y por semestre durante la formación siendo más notable esta dificultas en los semestres superiores que en los inferiores por la importancia que adquieren las competencias profesionales a este nivel y no las comunicativas.

La expresión oral es también afectada desde la misma aptitud del estudiante en el concepto de timidez la cual no le permite expresarse con facilidad y poder estructurar las ideas que quiere manifestar, dar a conocer o interpretar, en muchos de 
los casos no genera opinión de los argumentos sino que simplemente copia o repite otros conceptos sin apropiación de los suyos.

No conoce la relación que existe entre la expresión oral y la expresión escrita en las cuales nutre la preparación del profesional de la zootecnia desde la integralidad del perfil para el desarrollo de las competencias comunicativas, lo que permite que el estudiante no pueda interpretar, argumentar para generar coherencia y fluidez en la conversación que pueda iniciar.

La debilidad dentro de la estructura de las competencias comunicativas genera en el estudiante de la zootecnia una gran falencia dentro de la utilización de los elementos teóricos para poderlos utilizar y crear una estructura mental que le permite hacerse escuchar y hacerse entender.

Es necesario hacer más estudios de investigación en este tema pues es realmente preocupante como ha perdido valor el tema de las competencias comunicativas a tal nivel que ya se han manifestado en las pruebas mide las cuales arrojan un porcentaje muy bajo desde la lectura crítica, se deben plantear desde el comité curricular una estrategia de transversalidad desde las competencias para formar un buen profesional.

\section{FINANCIACIÓN}

Este artículo es fruto de la investigación desarrollada como Trabajo de Grado de la
Maestría en Práctica Pedagógica de la Universidad Francisco de Paula Santander Cúcuta, que lleva por nombre DESARROLLO DE LAS COMPETENCIAS COMUNICATIVAS EN ESTUDIANTES DE ZOOTECNIA DE LA UNIVERSIDAD FRANCISCO DE PAULA SANTANDER OCAÑA.

\section{BIBLIOGRAFÍA}

Acedo de Bueno, María de Lourdes. Algunas recomendaciones para la lectura comprensiva. [online]., 2008 [cited 09 de marzo 2010]. [Ciudad de Méjico, Méjico]. Available from internet: $<\mathrm{URL}$ : http://buenoacedo.homestead.com/files/Al gunas_recomendaciones_para_la_lectura_c ompr ensiva.htm>

Adultos, E. E. P., de Desarrollo Campesino, F. F., de Inversión Social, F. F., de Capacitación Técnica, F. F., al Género, I. D. H. R., de Desarrollo Humano, I. Í., ... \& de la Reforma Educativa, L. L. "Políticas educativas en materia de educación basada en competencias claves y laborales y su nivel de avance. Análisis y sistematización de las lecciones aprendidas en Bolivia”.

Aguirre de Ramirez, Rubiela. Dificultades de aprendizaje de la lectura y la escritura. Santafé de Bogotá. Universidad de los Andes, 2008. Disponible en: http://www.comunidadandina.org/bda/Fich aObra.aspx?cm=1272 
Alastre M., Dayana M. Comprensión de la lectura inicial. Consideraciones actitudinales acerca de la lectura y la escritura en el nivel de educación inicial. Santafé de Bogotá. Universidad de los Andes, 2007

Ardila Pérez, Hernando. El taller educativo. [online]., 2009 [cited 12 de marzo 2010]. [Bogotá, Colombia]. Available from internet: <URL: http://www.colombiaaprende.edu.co/html/ docentes/1596/article-164715.html>

Arredondo, Gonzalo. Una aproximación a la comprensión lectora. [online]., 2007 [cited 15 febrero 2010]. [Bogotá, Colombia]. Available from internet:<URL:

http://www.educared.edu.pe/planlector/Det alleInteres/1251/una-aproximacion-alconceptode-comprensio>

Ascencio Amaya, Y. M., \& Herrera, S. Y. (2006). Diseño de un programa escalafonario de remuneración para potencializar la motivación del personal docente de las instituciones de educación superior del sector privado de la ciudad de Santa Ana.

\section{Barria, Carlos. Competencias y habilidades para desarrollar la comprensión lectora. [online]., 2006 [cited 10 de marzo 2010]. [Barcelona, España]. Available from internet:<URL: http://www.rmm.cl/index_sub2.php?id_co}

ntenido=4121\&id_seccion $=1375$

\&id_portal=226>

Bezanilla, M. (2003). El proyecto Tuning $\mathrm{y}$ las competencias específicas.Seminario Internacional. Orientaciones pedagógicas para la convergencia europea de Educación Superior. Universidad de Deusto.

Bonilla Garcia, José Carlos. Libro fichas de comprensión lectora. Madrid (España) 2008. Disponible en: http://miauladept.blogspot.com/2008/09/li bro-fichas-comprensinlectora.html.

Bozu, Z., \& Herrera, P. J. C. (2009). El profesorado universitario en la sociedad del conocimiento: competencias profesionales docente. Revista de Formación e Innovación Educativa Universitaria (REFIEDU), 2(2), 221-231.

Briones, G. (1996). Investigación cuantitativa en las ciencias sociales. $e$ Impresores Ltda, Bogotá.

Camba, María Elena. ¿Cómo enseñar a leer comprensivamente en la esucela?. [online]., 2007 [cited 12 febrero 2010]. [Buenos Aires, Argentina]. Available from internet: < URL: http://aal.idoneos.com/index.php/Revista/ A\%C3\%B1o_9_Nro._ 9/Estrategias_de_pre_lectura> 
Carlino, Paula. Leer textos científicos y académicos en la educación superior: Obstáculos y bienvenidas a una cultura nueva cultura. [online]., 2009 [cited 05 de marzo 2009]. [Buenos Aires, Argentina]. Available from internet: $<$ URL:

http://asesoriapedagogica.ffyb.uba.ar/?q=le er-textos-cient-ficos-y-acad-micos-enlaeducaci-n-superior-obst-culos-ybienvenidas $>$

Carreira J.M. Metodología de muestreo. [online]., 2010 [cited 25 de junio 2010]. [Asturias, España]. Available from internet: $<\mathrm{URL}$ : http://www.hsa.es/id/investigacion/uai/uai _docs/muestreo/muestreo.htm>

Colorin Colorado. Los cinco componentes esenciales de la lectura. [online]., 2007 [cited 10 de marzo 2010]. [Washington, Estados Unidos]. Available from internet: $<\mathrm{URL}$ : http://www.colorincolorado.org/articulo/13 624>

\section{Crocco, Sonia. Directora} ESCUELA SECUNDARIA BÁSICA No. 09, Junín (Buenos Aires). Proyecto de comprensión lectora. [online]., 2010 [cited 20 junio 2010]. [Buenos Aires, Argentina]. Available from internet: $<\mathrm{URL}$ : http://www.esb9.com.ar/proyectos/laLectu raUnDesafioCompartido.php>
Denzin, N. K., \& Lincoln, Y. S. (2012). Manual de investigación cualitativa. Gedisa.

Deobold B., Van Dalen y MEYER, William J. La investigación descriptiva. [online]., 2006 [cited 20 de junio 2010]. [Méjico, Colombia]. Available from internet: <URL: http://noemagico.blogia.com/2006/091301 -la-investigacion-descriptiva.php>

Educación y pedagogía. Evolución histórica del concepto de comprensión lectora. [online]., 2009 [cited 13 de marzo 2010]. [Salamanca, España]. Available from internet: $<$ URL: http://html.rincondelvago.com/comprensio n-lectora.html>

Escuela País. Comprensión lectora. [online]., 2006 [cited 12 de marzo 2010]. [Bogotá, Colombia]. Available from internet: <URL: http://www.escuelapais.org/ edicionesanteriores/epatinta47/compresion v.php>

Fajardo Moreno, Flor Deyanira. Proyecto de integración "Quitar o poner...vamos a resolver". EDUTEKA, FUNDACIÓN GABRIEL PIEDRAHITA URIBE. ORTIZ PADILLA, [online]., 2010 [cited 22 junio de 2010]. [Bogotá, Colombia]. Available from internet:<URL: http://ww.eduteka.org/proyectos.php/2/436 
5?PHPSESSID=fe $8 \mathrm{bc} 4 \mathrm{a} 1$

9c8a8f314e10356a6b83c568>

Fundación Lee Colombia. Proyecto de lectura eficaz en el aula. [online]., 2008 [cited 21 de junio de 2010]. [Bogotá, Colombia]. Available from internet:<URL: http://www.fundacionleecolombia.com/pro yectolea.html>

García Esquivel, Iván. Ausubel, Piaget y Vygotsky. [online]., 2010 [cited 14 de marzo 2010]. [Bogotá, Colombia]. Available from internet: <URL: http: //www.monografias.com/trabajos43/piaget -ausubel-vygotsky/piagetausubelvygotsky.shtml>

Gobierno de Navarra, Ministerio de Educación. Proyecto para la mejora de las competencias implicadas en la lectura. [online]., 2008 [cited 20 junio 2010]. [Navarra, España]. Available from internet: $<\mathrm{URL}$ :

http://dpto.educacion.navarra.es/biblioteca sescolares/navarra_files/planrector\%20cast . pdf>

González Vargas, Benedicto. ¿Qué se entiende por comprensión lectora?. [online]., 2007 [cited 12 febrero 2010]. [Santiago, Chile]. Available from internet:<URL:

http://pedablogia.wordpress.com/2007/05/ 20/\%C2\%BFque-se-entiendeporcomprension-lectora/>
González, M. L. Capacidad de actuar e interacción. La pertinencia de un estudio interdisciplinar: fenomenología y neurofisiología1.

Gutiérrez Valencia, Ariel y MONTES DE OCA GARCÍA, Roberto, Universidad Juárez Autónoma de Tabasco, México. Importancia de la lectura. [online]., 2009 [cited 12 enero 2010]. [Ciudad de Méjico, Méjico]. Available from internet: $<\mathrm{URL}$ : http://www.rieoei.org/deloslectores/632Gu tierrez.PDF>

Hymes, D. (1971). Competence and performance in linguistic theory In Huxley'R. and Ingram, E.(eds): Language Acquisition, Models and Methods.

Jiménez M., Hermínsul (Profesor Asociado, Universidad del Amazonía). Investigación sobre enseñanza de la lengua y comprensión de lectura en Colombia. [online]., 2009 [cited 11 enero 2010]. [Florencia, Colombia]. Available from internet: $\quad<U R L$ : http://www.monografias.com/trabajos28/e nsenanza-lengua-comprension-lecturacolombia/ ensenanza-lengua-comprensionlectura-colombia.shtml>

Legrán, P. S., \& BÁSICAS, C. (2010). La competencia lingüística.

Londoño, M. A. P. (2003). Narrarse a sí mismo: residuo moderno en la 
hermenéutica de Paul Ricoeur. Folios: revista de la Facultad de Humanidades, (17), 47-56.

Londoño, M. P. Ensayos sobre hermenéutica y.

Martínez, José Daniel. La importancia del hábito de la comprensión lectora en la universidad. [online]., 2009 [cited 14 de marzo 2009]. [Santo Domingo, República Dominicana]. Available from internet: <URL: http://fuerzanacionalprogresista.blogspot.c om/2009/09/la-importancia-del-habitodela.html>

Mendoza Palacio, Rudy. PROYECTO TECNICAS DE LECTURA RENDIMIENTO ACADEMICO. [online]., 2006 [cited 10 de marzo 2010]. [Lima, Perú]. Available from internet:<URL:

http://proyectosytesis.ohlog.com/proyectotecnicas-delectura.oh11605.html>

Milos, P. (2003). Cómo articular competencias básicas y técnicas en la capacitación de jóvenes.

Muñoz Quiroz, J. C. (2010). La reflexión sobre las competencias docentes en el espacio de la práctica pedagógica de la licenciatura en diseño tecnológico.

Navarro Martínez, José María. La lectura y la escritura desde un enfoque constructivista. [online]., 2005 [cited 12 febrero 2010]. [Bogotá, Colombia]. Available from internet $:<\mathrm{URL}$ : http://ciberdocencia.gob.pe/index.php?id= $1289 \& a=$ articulo_completo $>$

Ortiz Padilla, Myriam. La competencia lectora de los estudiantes universitarios: un estudio para diseñar estrategias dirigidas a su perfeccionamiento. [online]., 2006 [cited 22 enero 2010]. [Bogotá, Colombia]. Available from internet: $<\mathrm{URL}$ : http://www.semanaciencia.info/article.php ?id_article $=154>$

Osoro, Kepa. Factores que inciden en la comprensión lectora. [online]., 2007 [cited 12 de marzo 2010]. [Barcelona, España]. Available from internet: <URL: http://sole.com/plec/documentos.php?id_d ocumento=17\&id_seccion $=5>$

Ospino Rihaza, I., \& Samper Ibáñez, J. (2014). Estrategia didactica para fortalecer las competencias ciudadanas a traves de la lectura critica en escenarios virtuales (Doctoral dissertation, Universidad de la Costa CUC).

Peña Borrero, Margarita. Examen de calidad de la educación superior, componente de comprensión lectora. [online]., 2009 [cited 12 febrero 2010]. [Bogotá, Colombia]. Available from internet:<URL:

http://web2.icfes.gov.co/index.php?option 
=com_docman\&task=doc_view $\&$ gid $=234$

$8 \&$ Ite $\operatorname{mid}=59>$

Pérez Esparrells, C. (2004). La educación universitaria en España: el vínculo entre financiación y calidad. Revista de educación.

Perrenoud, P. (2004). Desarrollar la práctica reflexiva en el oficio de enseñar: profesionalización y razón pedagógica (Vol. 1). Graó.

Poblete, M. (2003). La enseñanza basada en competencias. Competencias generales. Seminario. Internacional. Orientaciones pedagógicas para la convergencia europea de Educación Superior. Universidad de Deusto.

Polanco López, Nuria María. La comprensión y expresión de textos escritos. [online]., 2009 [cited 11 marzo 2010]. [Madrid, España]. Available from internet:<URL:

http://www.eumed.net/rev/ced/06/nmpl.ht $\mathrm{m}>$

Prada Londoño, M. A. (2009). De la lectura de textos a la comprensión de sí en la hermenéutica de Paul Ricoeur.

Publicaciones innovativas. Tipos de lectura. [online]., 2007 [cited 10 de marzo 2010]. [Caracas, Venezuela]. Available from http://comunidadlinguistica.blogspot.com/

2007/04/tipos-de-lecturas.html>

Quintana, Hilda E. Habilidades de comprensión. [online]., 2006 [cited 13 de marzo 2010]. [Barcelona, España]. Available from internet: $<\mathrm{URL}$ : http://www.espaciologopedico.com/articul os2.php?Id_articulo=1221>

Rada, Gabriel. Universidad Católica de Chile. Estudios descriptivos: Tipología. [online]., 2007 [cited 25 de junio 2010]. [Santiago, Chile]. Available from internet: <URL: http://escuela.med.puc.cl/recursos/recepide $\mathrm{m} / \mathrm{epiDesc} 4 . \mathrm{htm}>$

Reyzábal, M. V. (2016). Las competencias comunicativas y lingüísticas, clave para la calidad educativa. REICE. Revista Iberoamericana sobre Calidad, Eficacia y Cambio en Educación, 10(4).

Ricoeur, P. (1995). Teoría de la interpretación: discurso y excedente de sentido. Siglo XXI.

Ricoeur, P. (1996). Sí mismo como otro. Siglo XXI.

Sabino, Carlos. La entrevista. [online]., 2006 [cited 25 de junio 2010]. [Buenos Aires, Argentina]. Available from internet: <URL: http://html.rincondelvago.com/entrevista_3 .html>Sacristán, J. G. (2008). Educar por 
competencias, ¿ qué hay de nuevo?. Ediciones Morata.

Silva, Rosanna. Comprensión lectora. [online]., 2006 [cited 12 febrero 2010]. [Bogotá, Colombia]. Available from internet:<URL: http://www.monografias.com/trabajos38/c omprension-lectora/comprensionlectora3.shtml>

Tapia B., María Antonieta. Metodología de Investigación. [online]., 2000 [cited 25 de junio 2010]. [Santiago, Chile]. Available from internet: <URL: http://www.angelfire.com/emo/tomaustin/ Met/metinacap.htm>

Thompson, Iván. Tipos de encuesta. [online]., 2006 [cited 25 de junio 2010]. [Méjico, Méjico]. Available from internet: $<$ URL: http://www.promonegocios.net/mercadotec nia/encuestas-tipos.html>

Tobón, S. (2008). La formación basada en competencias en la educación superior: el enfoque complejo. México: Universidad Autónoma de Guadalajara.

Uribe Percy, Julian. Lectura a nivel mundial. [online]., 2009 [cited 12 enero 2010]. [Madrid, España]. Available from internet:<URL:

http://lecturaalda.blogspot.com/2009/01/lalectura-nivel-mundial.html>
Van Dijk, T. A. (1985). Semantic discourse analysis. Handbook of discourse analysis, 2, 103-136.

Vázquez Reina, Marta. Mejorar la comprensión lectora. [online]., 2009 [cited 15 enero 2010]. [Madrid, España]. Available from internet:<URL: http://www.consumer.es/web/es/educacion /extraescolar/2009/01/23/182909.php>

Vera, A., \& Villalón, M. (2005). La triangulación entre métodos cuantitativos y cualitativos en el proceso de investigación. Ciencia \& Trabajo [Internet], 7(16). 